\title{
A pilot study evaluating the prescribing of ceftriaxone in hospitals in Ghana: findings and implications.
}

${ }^{1}$ Daniel Kwame Afriyie, ${ }^{2}$ Seth Kwabena Amponsah, ${ }^{3}$ Justice Dogbey, ${ }^{1}$ Kwabena Agyekum,

${ }^{1}$ Samuel Kesse, ${ }^{4}$ Isle Truter, ${ }^{5}$ Joanna C Meyer, ${ }^{6,7,8^{*}}$ Brian Godman

${ }^{1}$ Ghana Police Hospital, Pharmacy Department, Accra, Ghana.

Emails:dspdan77@yahoo.com; agyekumkwabena@hotmail.com; kessejnr@gmail.com

${ }^{2}$ Department of Pharmacology and Toxicology, University of Ghana School of Pharmacy, Legon, Ghana. Email: sethicom@yahoo.com

${ }^{3}$ Korle-Bu Teaching Hospital, Plastics and Burns Unit, Pharmacy Department, Accra. Email: justdo12@yahoo.com

${ }^{4}$ Drug Utilization Research Unit (DURU), Department of Pharmacy, Nelson Mandela

Metropolitan University, Port Elizabeth 6031, South Africa. Email: ilse.truter@nmmu.ac.za

${ }^{5}$ Department of Pharmacy, SefakoMakgatho Health Sciences University, South Africa.

Email:hannelie.meyer@smu.ac.za

${ }^{6}$ Department of Clinical Pharmacology, Karolinska Institutet, Stockholm, Sweden. Email:

Brian Godman@ki.se

${ }^{7}$ Strathclyde Institute of Pharmacy and Biomedical Sciences, Strathclyde University,

Glasgow, UK. Email: Brian.Godman@strath.ac.uk

${ }^{8}$ Health Economics Centre, Liverpool University Management School, Liverpool University, United Kingdom

*Author for correspondence: Brian Godman, Division of Clinical Pharmacology, Karolinska Institute, Karolinska University Hospital Huddinge, SE-141 86, Stockholm, Sweden. Email: Brian.Godman@ki.se. Telephone + 468 58581068. Fax + 46859581070 and Strathclyde Institute of Pharmacy and Biomedical Sciences, University of Strathclyde, Glasgow G4 0RE, United Kingdom. Email: brian.godman@strath.ac.uk.

(Accepted for publication Hospital Practice. Please keep Confidential)

\begin{abstract}
Background and Objectives: Widespread empiric use of antibiotics exists especially in developing countries. This is a concern since inappropriate use of antibiotics, including their extended inappropriate use, will increase resistance rates. Consequently, there is a need to evaluate antibiotic utilisation across healthcare sectors to improve future use. This includes ceftriaxone in hospitals as it is a widely used antibiotic among hospitals including those in Ghana. Methods: A cross-sectional study to evaluate the appropriateness of ceftriaxone prescribing in a leading hospital in Ghana. Ceftriaxone prescribing in the patient record cards was assessed using modified WHO drug utilization evaluation criteria as well as referencing the national standard treatment guidelines in Ghana and the ceftriaxone package insert. Results: 251 patients were assessed. Ceftriaxone was most commonly prescribed for comorbid malaria with bacterial infections, urinary tract infections, sepsis and gastroenteritis. The appropriateness of the indication was $86.9 \%(\mathrm{n}=218)$. The doses most prescribed were $1 \mathrm{~g}$ $(41.4 \%)$ and $2 \mathrm{~g}(39.4 \%)$. Stat dose and once daily dosage regimen constituted $51.4 \%$ and $84.5 \%$ respectively. The most common duration of treatment was $1(51.4 \%)$ and 2 days $(35.1 \%)$. The overall appropriateness of prescribing was $93.0 \%$ against a pre-set threshold of 97.9\%. Conclusion: The appropriateness of ceftriaxone prescribing was high in this leading
\end{abstract}


hospital in Ghana. However, there is room for improvement with targeted educational initiatives, with further research planned.

Keywords: appropriateness, ceftriaxone, drug use evaluation, Ghana, thresholds.

\section{INTRODUCTION}

Irrational antimicrobial use is a global health problem especially in developing countries. It often results in failure to eradicate infectious microbes, emergence of antimicrobial resistance, as well as unnecessary health care cost to patients and healthcare systems [1-3]. Infections are also becoming increasingly difficult to treat with standard first-line antibiotics due to rising antimicrobial resistance (AMR) rates. This is resulting in the use of newer, more targeted, but also more expensive antibiotics across health care sectors $[1,4]$. Consequently, the evaluation of current antibiotic use is an essential measure for assessing and improving the appropriate use of antibiotics across sectors in order to develop pertinent future strategies to reduce AMR in the future [4-8].

Since the introduction of the rational drug use concept in the mid-1980's, several efforts have been made to improve prescribing practices in hospitals and other settings through promoting drug utilization studies, reviews or evaluation initiatives [9-13]. Drug utilization research is generally classified into descriptive (drug use patterns or trends) and analytical (drug use evaluation or review) studies. Drug use evaluation (DUE) is defined by the American Society of Health System Pharmacists (ASHP) as a criteria-based, ongoing and systemic process for monitoring and evaluating the prophylactic, therapeutic and empiric use of drugs (at the individual patient level) to ensure medicines are provided appropriately and used effectively $[14,15]$. According to the World Health Organization [16], this aspect is drug or disease specific or both, and can be structured to assess the prescribing, dispensing and administering of medications by indications, dose, and potential drug interaction among others. DUE can also be used to assess prescribing against agreed guidance, including both new and existing medicines [17-20].

Third-generation cephalosporins are used in the treatment of a number of infections due to their broad spectrum activity against most Gram-positive and Gram-negative bacteria. Ceftriaxone is the most prescribed antibiotic among the third generation cephalosporins and is often misused or overused [21-23]. In most developing countries such as Ghana, there is widespread empiric use of ceftriaxone among hospitalized patients as well as out-patients. This is because in most cases, culture and/or ceftriaxone antibiogram tests are unavailable.

Consequently, the rational use of ceftriaxone is of concern to prescribers and to health care systems, especially with the rising AMR rates in Ghana [24]. However, we are unaware of any study that has been published to assess the appropriateness of prescribing of ceftriaxone in hospitals in Ghana. This is important as ceftriaxone is on the national health insurance drug list, increasing the likelihood of this antibiotic being prescribed. Other antibiotics on the Ghana Police hospital formulary include amoxicillin, amoxicillin/clavulanic acid, cefuroxime, ciprofloxacin, doxycycline, flucloxacillin, gentamicin, and metronidazole.

We are aware that studies regarding antibiotic prescribing have been conducted in ambulatory care in Ghana, including self-medication, and there are also published studies monitoring antibiotic use and resistance patterns in Ghana [25-31]. We are also aware that the evaluation 
of the use of cephalosporins such as ceftriaxone is well documented in other countries, and has contributed to their prudent use and containing costs [5, 32-34].

The Standard Treatment Guidelines (STGs) of Ghana are published by the Ministry of Health to guide prescribers, pharmacists, dispensers and other healthcare staff who prescribe at primary healthcare facilities on the care of patients with common diseases, in line with the essential drug concept [35]. The STGs are primarily directed at physicians working in primary healthcare; however, they are also used in secondary and tertiary centres.

The use of the STGs to enhance the appropriate use of medicines is achieved through initiatives of the Ghana National Drugs Program. These include seminars for prescribers, advertisements in health magazines and supply of copies of the STGs to all health care facilities. The Police hospital, being a secondary level quasi-government health facility, has adopted the STGs and encourages prescribers to adhere to the guidelines through its clinical education unit where applicable. Drug package inserts are also used in other secondary and tertiary hospitals in Ghana to guide prescribing alongside the STGs where pertinent STGs do not exist. However, many health facilities in developing countries such as Ghana do not have active antibiotic stewardship programmes. These are considerations for the future. We are also aware that a number of studies have shown low adherence levels to STGs [36,37].

Consequently, the aim of this study was to evaluate the current use of ceftriaxone within a national Police referral hospital in Ghana against published guidance. The findings will act as a basis for suggesting future initiatives to further promote its rational use in Ghana if applicable along with general moves to enhance antibiotic stewardship.

\section{METHODS}

\section{Study site}

The study was conducted at the Ghana Police Hospital, Greater Accra, Ghana. The Greater Region is the smallest area of Ghana's administrative region, occupying a total land surface area of $3,245 \mathrm{~km}^{2}$, representing $1.4 \%$ of the total area of Ghana. The population of the region stood at just over 4 million people in 2012. There is one tertiary level referral health facility in Accra, one regional hospital, two quasi-government secondary level security hospitals, and a few private hospitals with limited in-service facilities. The Ghana Police hospital is a 100-bed facility providing health services to police personnel, their dependents, and the general public. Some of the specialist services in addition to outpatient services include gynaecological, surgical, paediatric, family medicine, dental, public health, ophthalmological and ear-nosethroat services among others. The out-patient department provides services to over 100,000 patients each year, representing an estimated $2.5 \%$ of the total population of the Greater Accra region. The hospital is currently undergoing expansion to cope with increasing service demands. It also serves as a major medical referral centre during national disasters. Consequently, the results of the study can provide a basis for assessing current ceftriaxone use within hospitals in Ghana in order to develop future strategies to improve the use of ceftriaxone in this and other hospitals in Ghana if pertinent.

\section{Study design}

This was a cross-sectional study conducted from January to June 2015. This study evaluated ceftriaxone injection use with the aid of the Pharmacy Department's drug evaluation data collection format. This included pre-set criteria for assessing ceftriaxone use based on the 
National STGs [35], and ceftriaxone injection package insert from Roche Laboratories [Batch number: B0008B02F93].

Data collection and determination of thresholds of key variables.

Patient cards with prescribed ceftriaxone injections from both out- and in-patient presented at the Pharmacy Department of the Ghana Police Hospital were assessed on receipt with the aid of the Pharmacy unit's drug evaluation form. Demographic information, diagnosis, drug dose, drug frequency, duration of treatment supportive/additional antibiotics, possible drug interactions and disease contraindications were obtained from the patient cards.

A modified version of the World Health Organization (WHO) criteria was adopted for the drug use evaluation [38]. In line with WHO criteria for assessing medicine in the absence of hospital specific STG's, we based our criteria on recommendations from the national STGs, which is principally aimed at primary care, in addition to manufacturer's package insert. These two sources are seen as relevant literature sources for prescribers guidance in this setting. Hence, prescribing of ceftriaxone was considered appropriate if this was in line with the recommendations in the STGs and the manufacturer's package insert.

Furthermore, the actual thresholds of prescribed ceftriaxone with respect to diagnosis, dose, frequency, duration, need for supportive/additional antibiotics, possible drug interactions and contraindications were determined and assessed against pre-set criteria thresholds ranging between 95-100\%. This threshold was based on the WHO and Management Sciences for Health guidelines for the evaluation of drug use in hospitals [39]. Patient cards not bearing any of the required data on sex, age, drug dose, drug frequency, duration of treatment and diagnosis, were excluded.

\section{$\%$ Actual Threshold $=\underline{\text { Total observed appropriateness of each variable }} \times 100$. Total expected appropriateness of each variable}

There was no attempt to assess the accuracy of the diagnosis stated on the patient cards as this was a drug use evaluation study based on the actual data included in the record cards and did not involve interviews with physicians or other professionals. Some of these anyway may have left the hospital to practice elsewhere by the time the data was analysed.

\section{Statistical analysis}

Data generated from patient cards were categorized and analyzed with the aid of Excel spreadsheet (Microsoft Excel 2010), after verification and cleaning. Descriptive statistics (percentages, frequency and histograms) was used to analyze the data.

\section{Ethical consideration}

The study protocol received approval from the Ghana Police Hospital Administration. Patients' data were handled with utmost confidentiality, and all patients and doctors identifiers were removed.

\section{RESULTS}

\section{Demography of patients}

Out of the 276 patients whose cards were reviewed within the study period which had ceftriaxone injection prescribed, $251(90 \%)$ had all the relevant information required for inclusion in the evaluation of ceftriaxone use. In- and out-patients who were prescribed ceftriaxone injection constituted $12.4 \%$ (31) and $87.6 \%$ (220) of patients respectively. The 
age category with the highest prescription of ceftriaxone was $21-\leq 40$ years $(n=95,37.8 \%)$ whilst the age category with the least ceftriaxone prescriptions $(n=22,8.8 \%)$ were patients older than 60 years. The gender and age categories of patients whose cards had ceftriaxone injection prescribed are shown in Table 1.

Table 1: Gender and age characteristics of study patients prescribed ceftriaxone = 251)

\begin{tabular}{|l|c|c|}
\hline Characteristics & \multirow{2}{*}{ Frequency } & Percentage (\%) \\
\cline { 1 - 1 } Gender & 133 & 53.0 \\
\hline Male & 118 & 47.0 \\
\hline Female & & \\
\hline Age Category & 32 & 12.8 \\
\hline 4 months to $\leq 5$ years & 37 & 14.7 \\
\hline$>5$ years to $\leq 13$ years & 22 & 8.8 \\
\hline$>13$ years to $\leq 20$ years & 95 & 37.8 \\
\hline$>20$ years to $\leq 40$ years & 41 & 16.3 \\
\hline$>40$ years to $\leq 60$ years & 24 & 9.6 \\
\hline$>61$ years & & \\
\hline
\end{tabular}

\section{Common indications for which ceftriaxone was prescribed}

Patients diagnosed as having malaria with other bacterial infections $(19.9 \%)$, urinary tract infections $(11.6 \%)$, sepsis $(9.6 \%)$ gastroenteritis $(8.6 \%)$, upper respiratory tract infection (5.6\%), appendicitis $(4.8 \%)$, gastritis $(3.2 \%)$, food poisoning $(2.4 \%)$, fracture $(2.4 \%)$, cellulitis $(2.4 \%)$ and enteric fever $(2.4 \%)$ were the prevalent clinical conditions for which ceftriaxone was mostly prescribed. These top eleven indications for which ceftriaxone was prescribed constituted $72.9 \%$ (183) of the cases. Other conditions for which ceftriaxone was prescribed $(\mathrm{n}<6$ per diagnosis, 2.4\%) constituted $27.1 \%(\mathrm{n}=68)$. These included gonorrhoea, uterine fibroid, prostate infections, tonsillitis, appendisectomy, leukopenia, urethral discharge, herpes zoster, Stevens-Johnson's syndrome and breast cancer.

\section{Appropriateness of the indication}

The overall appropriateness of indications for which ceftriaxone was prescribed based on our methodology was $86.9 \%(n=218)$, whilst $13.1 \%(n=33)$ were inappropriate (Table 2).

Most of the malaria cases were diagnosed as co-morbid $78.0 \%(n=39)$ with bacterial infections such as gastroenteritis, urinary tract infections, bacterial suspected food poisoning, sepsis, meningitis, gonorrhoea and typhoid. The remaining malaria cases with suspected bacterial infections but not stated on the patients' cards constituted $22.0 \%(\mathrm{n}=11)$. Consequently, indications for prescribing in these cases were regarded as inappropriate. In the remaining frequent cases for which ceftriaxone was prescribed, it was observed that the prescriptions were appropriate $(100 \%)$.

Furthermore, in the least diagnosed cases in this study ( $\mathrm{n}<6$ per diagnosis) which together constituted $27.1 \%$ of prescriptions, the indications for which prescriptions for ceftriaxone was appropriate constituted 46 (67.7\%), whilst 22 (32.3\%) were inappropriate e.g. diabetes, hypertension, stroke and herpes zoster. The detailed results of the appropriateness of prescribed ceftriaxone injections are presented in Table 2. 
Table 2: Appropriateness of indications for ceftriaxone injection prescribing $(n=251)$.

\begin{tabular}{|l|c|c|c|c|}
\hline Diagnosis & $\begin{array}{c}\text { Total } \\
\text { number }\end{array}$ & $\begin{array}{c}\text { Number } \\
\text { appropriate }\end{array}$ & $\begin{array}{c}\text { Percentage } \\
\mathbf{( \% )} \\
\text { appropriate }\end{array}$ & $\begin{array}{c}\text { Percentage } \\
\text { (\%) } \\
\text { inappropriate }\end{array}$ \\
\hline $\begin{array}{l}\text { Co-morbidity } \\
\text { (Malaria + other } \\
\text { bacterial infections) }\end{array}$ & 50 & 39 & $78.0 \%$ & $22.0 \%$ \\
\hline $\begin{array}{l}\text { Urinary tract } \\
\text { infection }\end{array}$ & 29 & 29 & $100 \%$ & - \\
\hline Sepsis & 24 & 24 & $100 \%$ & - \\
\hline Gastroenteritis & 22 & 22 & $100 \%$ & - \\
\hline $\begin{array}{l}\text { Upper respiratory } \\
\text { tract infection }\end{array}$ & 14 & 14 & $100 \%$ & - \\
\hline Appendicitis & 12 & 12 & $100 \%$ & - \\
\hline Gastritis & 8 & 8 & $100 \%$ & - \\
\hline Food poisoning & 6 & 8 & $100 \%$ & - \\
\hline $\begin{array}{l}\text { Fracture (Bone } \\
\text { infection) }\end{array}$ & 6 & 6 & $100 \%$ & - \\
\hline Cellulitis & 6 & 6 & $100 \%$ & - \\
\hline Enteric fever & 6 & 6 & $100 \%$ & - \\
\hline Others & 68 & 46 & $67.7 \%$ & $32.3 \%$ \\
\hline Total & 251 & 218 & $86.9 \%$ & $13.1 \%$ \\
\hline
\end{tabular}

\section{Pattern of prescribed ceftriaxone doses}

With respect to prescribed doses of ceftriaxone observed in this study, $1 \mathrm{~g}(41.4 \%)$ and $2 \mathrm{~g}$ (39.4\%) were found to be the most prescribed doses of ceftriaxone, followed by $500 \mathrm{mg}(9.2 \%)$ and $(5.6 \%)$ respectively. The least prescribed doses were $125 \mathrm{mg}, 3 \mathrm{~g}$ and $4 \mathrm{~g}$, which together constituted $4.4 \%$ of the doses prescribed.

\section{Daily frequency and duration of prescribed ceftriaxone.}

With respect to the daily dosage regimen, ceftriaxone stat doses (administered once) constituted $51.4 \%$ (129 prescriptions) whilst once daily regimens which were prescribed (as stat only or stat and once daily) constituted $84.5 \%$ (212 prescriptions). Twice daily dosage regimens in equally divided doses every 12 hours constituted $10.3 \%$ (26 prescriptions), and other doses which given as twice daily or start then twice daily were 5.2\% (13). Ceftriaxone prescribed for 1 day constituted $51.4 \%$ (129), whilst prescriptions for two days was $35.1 \%(88)$ and three to five days was $13.5 \%$ (34).

\section{Actual threshold and pre-set criteria threshold}

The study revealed that the actual threshold of prescribed ceftriaxone injections was $86.9 \%$ with respect to the appropriateness of the indication (diagnosis) versus the pre-set threshold of $95 \%$. Actual thresholds for all the doses and daily dosage regimen were appropriate $(100 \%)$. The actual threshold for duration of prescribed ceftriaxone was $85.7 \%$ against the pre-set threshold of $95 \%$. The actual threshold for prescribed supportive or additional antibiotics in this study was $90.3 \%$ against a pre-set threshold of $100 \%$. The threshold obtained for the absence of possible drug-drug interactions was $87.7 \%$ against a pre-set threshold of $95 \%$. There was no disease condition for which prescribed ceftriaxone was contraindicated, hence a threshold of $100 \%$. The detailed comparison of actual and pre-set criteria thresholds is shown in Table 3. 
Table 3: Criteria threshold for ceftriaxone injection use at the Ghana Police Hospital

\begin{tabular}{|c|c|c|c|}
\hline $\begin{array}{c}\text { Criteria assessed } \\
\text { variables }\end{array}$ & $\begin{array}{c}\text { Number of cases } \\
\text { assessed }\end{array}$ & $\begin{array}{c}\text { \% Pre-set } \\
\text { Threshold }\end{array}$ & $\begin{array}{c}\text { \% Actual } \\
\text { Threshold }\end{array}$ \\
\hline Indication & 251 & $239(95 \%)$ & $(218) 86.9 \%$ \\
\hline Dose (based on age) & 251 & $251(100 \%)$ & $(251) 100 \%$ \\
\hline Daily dose regimen & 251 & $251(100 \%)$ & $(251) 100 \%$ \\
\hline $\begin{array}{c}\text { Duration (based on } \\
\text { severity of condition) }\end{array}$ & 251 & $239(95 \%)$ & $(215) 85.7 \%$ \\
\hline $\begin{array}{c}\text { Supportive/additional } \\
\text { antibiotic required }\end{array}$ & 186 & $186(100 \%)$ & $168(90.3 \%)$ \\
\hline $\begin{array}{c}\text { Possible drug-drug } \\
\text { Interaction (absence) }\end{array}$ & 251 & $239(95 \%)$ & $(220) 87.7 \%$ \\
\hline $\begin{array}{c}\text { Contraindicated Disease } \\
\text { (absence) }\end{array}$ & 251 & $251(100 \%)$ & $(251) 100 \%$ \\
\hline Overall appropriateness & 1692 & $1656 / 1692(97.9 \%)$ & $1574 / 1692(93.0 \%)$ \\
\hline
\end{tabular}

*NB. The criteria for assessing variables was as specified in STGs and ceftriaxone package insert.

\section{DISCUSSION}

Drug use evaluation involves a thorough review of patients' prescription and medication data before, during and after dispensing in order to assure appropriate therapeutic decision-making and positive outcomes [40]. According to the WHO [38], the credibility and acceptance of drug use evaluation depends on using criteria developed from established evidenced based medicines from reputable sources. Furthermore, the criteria for use of any medicine must be established using health facilities STGs. Other sources for developing criteria in the absence hospital STGs are recommendations from national, locally available satisfactory drug use protocols, other relevant literature sources and/or recognised international or local experts.

In this study, malaria with suspected bacterial infections such as upper respiratory tract infections (URTIs), typhoid, sepsis, gastroenteritis and gonorrhoea among others, constituted $19.9 \%$ of the indications for which ceftriaxone was prescribed in hospitals in Ghana. However, we could not determine whether the diagnosis of malaria with suspected bacterial infections was always supported by the results of rapid diagnostic tests and laboratory culture results as this was not always recorded. This will be an area of focus in the future.

Comorbid and non-comorbid diagnosis in a similar ceftriaxone evaluation study in Nepal was found to constitute $27.8 \%$ and $72.2 \%$ respectively [41]. Indications such as URTI-pneumonia $(20.9 \%)$ and sepsis $(20.9 \%)$ were higher than our study, though the frequency of UTIs $(9.8 \%)$ and typhoid fever $(2.7 \%)$ were comparable [42]. This though may be down to casemix differences between the two populations.

Overall, the appropriateness of indications for which ceftriaxone injection was prescribed was $86.9 \%$ in this study (Table 3), and may be because we included the package insert to help determine appropriateness, and there have been educational activities to enhance appropriate prescribing of ceftriaxone. 
The appropriateness of prescribed ceftriaxone with respect to indication, dose, frequency, duration, supportive/complementary antibiotic therapy, possible drug-drug interactions and contraindications was also high at $93 \%$. This appreciably higher than $48.9 \%$ and $44.6 \%$ obtained from a similar study in public and private hospitals in Ethiopia [48]. This was despite our study including three additional variables in the determination of overall appropriateness of ceftriaxone prescribed. However, Shimels et al used their national STGs as their reference point. Other studies have also documented lower rates of appropriateness of prescribed ceftriaxone, for example, $38 \%$ in a tertiary hospital at Port Spain, Trinidad [44] and 35.8\% at Ayder Referral Hospital, Ethiopia [42]. Abebe et al based their appropriateness of ceftriaxone use on the indication, dose, frequency and duration against the Ethiopian STGs only.

Higher levels of the appropriateness of prescribed ceftriaxone have though been seen in other studies, e.g. 73.02\% and 65.5\% at the Police Hospital, Addis Ababa [45], and in a survey of 10 Korean hospitals [5] respectively; lower though than seen in our study. This again may be due to the inclusion of the ceftriaxone package insert in our study coupled with previous activities. Having said this, further analysis of our study showed that if the appropriateness of prescribed ceftriaxone was assessed against only the indication, dose, daily dose regimen and duration of therapy, as seen in other studies reported in Africa, the appropriateness of use would have been $96.7 \%$ instead of $93 \%$. This suggests that the number of variables used to determine appropriateness of a prescribed medicine will appreciably influence guideline adherence rates.

Unstated suspected bacterial co-infection on patient cards could be an underlying reason why ceftriaxone was being prescribed in some the cases, which were inappropriate by our criteria. This will be addressed in future studies.

Interestingly, most of the indications for which ceftriaxone was being prescribed in our study were not in the national STGs; however, justification was based on the ceftriaxone package insert. The main reason for this current situation could be that the aim of national STGs is to ensure the use of affordable and effective medicines, in line with the concept of an essential medicine list, and primarily aimed at ambulatory care. The hospital situation can be different.

Common erroneous drug dosage regimens, which include prescribing of sub-therapeutic or excessive doses, as well as the wrong frequency of administration, have been associated with antimicrobial therapy [56]. However, our study showed that all doses prescribed for infants, children and adults were in line with the reference sources. In addition, $84.5 \%$ of the doses were prescribed once daily (every 24 hours), whilst $15.5 \%$ were prescribed twice daily. Furthermore, $80.8 \%$ of the doses prescribed were either 1 or $2 \mathrm{~g}$, suggesting most of the patients in this study were over 12 years, which appears to agree with our demographic data which revealed that $72.5 \%$ of patients were older than 13 years (Table 1). Instances of high doses of 3-4 g were observed, but these were rationally prescribed for the management of meningitis in adults. This again endorses the appropriate use of ceftriaxone that was generally seen in our study.

Reports have shown that duration of antibiotic use correlates with resistance prevalence [4648]. Hence, adherence to minimum required duration of antibiotics therapy can mitigate against the development of resistance by microorganisms. In our study, ceftriaxone was prescribed once daily for either 1 or 2 days in $86.5 \%$ of the cases, whilst prescriptions for 3 5 days constituted $13.5 \%$. Overall, $87.6 \%$ of prescribed ceftriaxone injections were given in outpatients for short courses. As a result, it was not surprising that $74.1 \%$ of cases required supportive or additional antibiotics to complete patient treatment. The relatively high cost of 
ceftriaxone to patients and the healthcare system, coupled with most of the cases seen on an outpatient basis, could be the reason underpinning the need to continue initial ceftriaxone injections with oral antibiotics in most patients. However, if these outpatients fail to comply with the supportive or additional oral antibiotics after their initial dose of ceftriaxone, this could contribute antimicrobial resistance to ceftriaxone unless addressed. Common antibiotics that were often prescribed with ceftriaxone included ciprofloxacin, penicillin, metronidazole, doxycycline, cefuroxime, amoxicillin and ciprofloxacin-tinidazole. This will be explored further in future research projects to improve antibiotic prescribing as part of stewardship programmes.

Establishing criteria for evaluating medicine use based on evidence based sources, recognized international and local experts' remains the most important procedure in DUE [39]. In addition, setting a threshold of $90-95 \%$ for each criteria, against which the actual threshold is determined, is seen as appropriate to assess rational drug use to optimize future use [39]. However, most DUE studies often end with determination of percentages of appropriateness and inappropriateness but fail to fulfil the WHO-MSH requirement of determining actual thresholds against pre-set thresholds. In this study, the overall actual threshold for all the drug use indicators was $93.0 \%$ as against an expected threshold of $97.9 \%$.

Overall, there appeared to be a high level of rational use of ceftriaxone at the Police hospital in Ghana, based on the percentage appropriateness of all the criteria variables, which ranged from $85.7 \%$ to $100 \%$ (Table 3 ). Whilst the high overall target (threshold) of $97.9 \%$ was not attained, the overall rate of rational use of ceftriaxone injection for the individual indicators was high. However, there was some inappropriate prescribing. The most common was the duration of therapy, followed closely by inappropriate indications. This was similar to studies in Ethiopia $[42,43,45]$ and Thailand [49]. 74.1\% (186) of the cases in which ceftriaxone was prescribed also required additional or supportive antibiotics to complete drug therapy. This means prescribers in the future should ensure that adequate and appropriate complementary antibiotics are prescribed together with ceftriaxone to complete drug therapy. This will be a target for the future with threshold rates enhanced through targeted educational activities.

The possibility of incompatibility of ceftriaxone with calcium containing solutions such as Hartmann's solution or Ringer's solution, amscarine, vancomycin, fluconazole and aminoglycosides is cautioned in the package insert. Co-prescribing with Ringer's lactate was seen in $12.4 \%$ of prescriptions, lower though than rates of $40.9 \%$ to $44.5 \%$ in Ethiopia [43]. The actual threshold obtained for the absence of possible drug-drug interactions was $87.7 \%$ compared to the minimum expected pre-set threshold of $95 \%$. Consequently, there is a need for prescribers to continue to minimize such co-prescriptions and use alternative maintenance fluids where pertinent. However, no such adverse reports (drug incompatibility effects) were reported within the study period. With respect to contraindications to ceftriaxone prescribing, no such instances were observed in this study; consequently, the actual and the pre-set thresholds were the same at $100 \%$, which is encouraging.

We accept that there are major limitations in our study. These include the fact that the study was only carried out in only one centre in Ghana and for only six months reducing the potential to record any seasonality. We also accept that we did not assess how diagnoses stated on patient cards were made, just the diagnosis. This may well have resulted in higher adherence rates in view of the broad categories of infection within the package insert. We also did not capture patients who should have been prescribed ceftriaxone but were prescribed other antibiotics, neither did we capture when ceftriaxone was started, which is important to optimise its use in 
sepsis and pneumonia. We also did not segment patients into in- and out-patients given the relatively small number of in-patients given ceftriaxone. However, in view of the nature of the hospital, and its referral nature, as well as the number of prescriptions analysed, we believe our findings are valid and provide direction for the future. We will though be undertaking future studies among hospitals in Ghana to further assess the appropriateness of ceftriaxone injections using more rigorous criteria. This includes antibiograms as well as upgraded treatment guidance including timings. There will also be targeted education interventions in our hospitals based on this and future activities including the duration of therapy, wrong indication or unstated comorbid indications. The impact of these activities will be assessed to further improve antibiotic use among hospitals in Ghana. We also hope our findings will be of interest to other African countries as they seek to improve antibiotic use in their hospitals.

\section{CONCLUSION}

The study revealed that the appropriateness of ceftriaxone prescribed (duration and indications) was lower than expected. Having said this, pre-set levels were high at $95 \%$ to $100 \%$ based on WHO and MSH recommendations. We believe our findings can be exported to other hospitals in Ghana to improve their utilisation of ceftriaxone. Findings of ceftriaxone-use-related problems in this study also provide a rational for further targeted education of prescribers and other health care workers at the Ghana Police Hospital as well as other hospitals in Ghana. Such programs will be the subject of future research activities in this and other hospitals in Ghana to attain agreed pre-set levels. This will form part of future antibiotic stewardship programmes.

\section{Key Messages}

- Several rational drug use studies conducted in Ghana have revealed high proportions of antibiotics on prescriptions, appreciably above national and WHO indices per prescription.

- Ceftriaxone injection is among the most frequently prescribed antibiotic in Ghana due to its known efficacy and safety profile, coupled with its once or twice -daily ease of administration.

- The Pharmacy Department, of the National Police Hospital which is also a referral hospital during national disaster, conducted a cross-sectional study in its facility on the evaluation of ceftriaxone injection from January to June 2015.

- The observed threshold of appropriateness of ceftriaxone prescribed was $93.0 \%$ as against expected (pre-set) threshold of $97.9 \%$. Inappropriate indication and duration of prescribing were identified as most common areas with prescribing errors.

- Though findings suggest high adherence to STGs and ceftriaxone package insert recommendations. However, targeted education of prescribers could further improve its prescribing at the facility especially in outpatients

- The findings of this study provides baseline data for similar studies among secondary and tertiary health facilities in Ghana in addition to this hospital including the potential instigation of antibiotic stewardship programmes 


\section{REFERENCES}

1. Md Rezal RS, Hassali MA, ALrasheedy AA, et al. Physicians knowledge, perceptions and behavior towards antibiotic prescribing: systematic review of the literature. Expert Rev Anti Infect. Ther 2015; 13 (5): 665-680.

2. Ghandra S, Barter DM, Laxminarayan R. Economic burden of antibiotic resistance: how much do we really know? Clin Microbiol Infect. 2014; 20 (10): 973-980.

3. World Health Organization (WHO). Partnerships for malaria control: engaging the formal and informal private sectors in child survival, 2006. WHO Ref. No: TDR/GEN/06.1, World Health Organization, Geneva.

4. Bisht R, Katiyar A, Singh R, et al. Antibiotic resistance - A global issue of concern. Asian J Pharm and Clinical Res. 2009; 2:34-39.

5. Lee H, Jung D, Yeom JS. Evaluation of ceftriaxone utilization at muliticenter study. Korean J Intern Med. 2009; 24 (4): 374-380

6. McNeil V, Cruickshank M, Duguid M. Safer use of antimicrobials in hospitals: the value of antimicrobial usage data. The Medical journal of Australia. 2010;193(8 Suppl):S114-7.

7. Raastad R, Tvete IF, Abrahamsen TG, Berild D, Leegaard TM, Walberg M, et al. A worrying trend in weight-adjusted paediatric antibiotic use in a Norwegian tertiary care hospital. Acta paediatrica (Oslo, Norway : 1992). 2015;104(7):687-92

8. Khan FA, Singh VK, Sharma S, Singh P. A prospective study on the antimicrobial usage in the medicine department of a tertiary care teaching hospital. Journal of clinical and diagnostic research : JCDR. 2013;7(7):1343-6.

9. Laing RO. Rational drug use: an unsolved problem. Trop Doct. 1990; 20: 101-103.

10. Walker GJ, Hogerzeil HV, Sallami AO, et al. Evaluation of rational drug prescribing in Democratic Yemen. Soc Sci Med. 1990; 31 (7): 823-828

11. Massele A, Burger J, Katende-Kyenda NL, Kalemeera F, Kenaope T, Kibuule D, Mbach O, Mubita M, Oluka M, Olusanya A, Anand Paramadhas B, van Zyl P, Godman B. Outcome of the first Medicines Utilisation Research in Africa Group meeting to promote sustainable and rational medicine use in Africa. Expert Rev Pharmacoecon Outcomes Res. 2015; 15(6):885-8

12. Samilski JAE, Lau TTY, Elbe DHT, Aulakh AK, Lun EMC. Drug Use Evaluation of Moxifloxacin (Avelox) Using a Hand-Held Electronic Device At a Canadian Teaching Hospital. Pharmacy and Therapeutics. 2012;37(5):291-9.

13. Salehifar E, Shiva A, Moshayedi M, Kashi TS, Chabra A. Drug use evaluation of Meropenem at a tertiary care university hospital: A report from Northern Iran. Journal of Research in Pharmacy Practice. 2015;4(4):222-5

14. American Society of Hospital Pharmacists. ASHP guidelines on the pharmacist's role in drug use evaluation. Amer J Hosp Pharm. 1988; 45: 385-386.

15. American Society of Hospital Pharmacists (ASHP). Criteria for drug use evaluation. Vol. 1. Bethesda: American Society of Hospital Pharmacists, 1990.

16. World Health Organization (WHO). Drug and therapeutic committee. A practical guide to drug use evaluation; Drug use evaluation (Drug utilization review), 2003; 155. Available at URL: http://apps.who.int/medicinedocs/en/d/Js4882e/

17. Godman B, Malmstrom RE, Diogene E, et al. Are new models needed to optimize the utilization of new medicines to sustain healthcare systems? Expert Rev Clin Pharmacol. 2015; 8 (1):77-94.

18. Godman B, Malmstrom RE, Diogene E, et al. Diabigatran-a continuing exemplary case history demonstrating the need for comprehensive models to optimize the utilization of new drugs. Front Pharmacol. 2014; 5:109. 
19. Godman B, Wettermark B, van Woekom M, et al. Multiple policies to enhance prescribing efficiency for established medicines in Europe with a particular focus on demand-side measures: findings and future implications. Front Pharmacol. 2014; 5:106.

20. SHPA Standard of practice for drug use evaluation in Australian Hospital. J Pharm Pract Res. 2004; 34 (3): 220-223.

21. Khaled AI, Abdulkarim A, Noohu K, et al. Misuse of antibiotics and awareness of antibiotics hazard among the public and medical professionals in Thamar Province in Republic of Yemen. IJCP. 2013; 4 (1): ISSN 0976-8157.

22. Salah I. Cephalosporins usage and resistance in Sudanese hospital surgical wards. J Pharm Biomed Sci. 2011; 3: 2230-7885.

23. William F, Janis E. The cephalosporins. Mayo Clin Proc 1999; 74: 187-195.

24. Gyansa-Lutterodt M. Antibiotic resistance in Ghana. Lancet Infect Dis. 2013; 13 (12): 1006-1007.

25. Ahiabu MA, Tersbol BP, Biritwum R, et al. A retrospective audit of antibiotic prescriptions primary health-care facilities in Eastern Region, Ghana. Health Policy Plan. 2016; 31 (2): 250-258.

26. Donkor ES, Tetteh-Quarcoo PB, Nartey P, et al. Self-medication practices with antibiotics among tertiary level students in Accra, Ghana: a cross-sectional study. IJERPH. 2012; 9 (10): 3519-29.

27. Afriyie DK, Gyansa-Lutterodt M, Amponsah SK, et al. Susceptibility pattern of uropathogens to ciprofloxacin at the Ghana Police Hospital. PAMJ. 2015; 22:87.

28. Namboodiri SS, Opintan JA, Lijek RS, et al. Quinolone resistance in Escherichia coli from Accra, Ghana. BMC Microbiol. 2011; 11: 44.

29. Newman MJ, Frimpong E, Donkor ES, et al. Resistance to antimicrobial drugs in Ghana. Infection and Drug Resistance. 2011:4 215-220

30. George DF, Gbedema SY, Agyare C, et al. Antibiotic Resistance Patterns of Escherichia coli Isolates from Hospitals in Kumasi, Ghana. ISRN Microbiology. 2012: 1-5. Article ID 658470

31. Saana ABBM, Adu F, Agyare C, et al. Antibiotic resistance patterns of strains of Staphylococcus aureus isolated from patients in three hospitals in Kumasi, Ghana. Journal of Bacteriology Research. 2013; 5 (3): 35-40.

32. Reddy SC, Sankar, BK, Ambujakshi HR, et al. A study on prescription pattern of ceftriaxone in general medicine department of a south Indian teaching hospital. IJRPB. 2015; 3(2): 130-133.

33. Ayinalem GA, Gelaw BK, Belay AZ, et al. Drug use evaluation of ceftriaxone in medical ward of Dessie Referral Hospital, North East Ethiopia. Int J Basic Clin Pharmacol. 2013; 2 (6): 711-717.

34. Misan GM, Dollman C, Shaw DR, et al. Cephalosporin utilization review and evaluation. Pharmacoeconomics 1995; 8:100-122.

35. Ministry of Health Republic of Ghana. Standard Treatment Guidelines. Sixth Edition, Ghana. 2010. Available at URL: http://apps.who.int/medicinedocs/documents/s18015en/s18015en.pdf

36. Hashemi S, Nasrollah A, Rajabi M. Irrational antibiotic prescribing. A local issue or global concern? EXCLI Journal 2013; 12: 384-395.

37. Ntsekhe MN, Hoohlo-Kotle N, Tlali et al. Antibiotic Prescribing Patterns at Six Hospitals in Lesotho. Submitted to the US Agency for International Development by the Strengthening Pharmaceutical Systems (SPS) Program. Arlington, VA 2011: Management Sciences for Health. 
38. Holloway K, Green T. Drug and Therapeutics Committees- A Practical Guide. Geneva, Switzerland: World Health Organization. Department of Essential Drugs and Medicines Policy 2003.

39. Management Sciences for Health and World Health Organization. Drug and Therapeutics Committee Training Course. Submitted to U.S Agency for International Development by the Rational Pharmaceutical Management Plus Program. Arlington, VA 2007: 229 - 240. URL: http://apps.who.int/medicinedocs/documents/s22115en/s22115en.pdf

40. Academy of Managed Care Pharmacy. Drug Utilization Review.. Available at URL: http://www.amcp.org/WorkArea/DownloadAsset.aspx?id=9296

41. Srijana G, Nijan U, Sabyata G et al. A study on drug use of ceftriaxone in a private hospital of Nepal. World J Pharm Sci. 2015; 3(1): 111-119.

42. Abebe FA, Derbew F, Berhe DF, et al. Drug use evaluation of ceftriaxone: the case of Ayder Referral Hospital, Mikelle, Ethiopia. IJPSR 2012; 3:2191-195.

43. Shimels T, Bilal A, Mulugeta A. Evaluation of ceftriaxone utilization in internal medicine wards of general hospitals in Addis Ababa, Ethiopia: a comparative retrospective study. $\mathrm{J}$ Pharm Policy and Pract. 2015; 8: 26.

44. Pinto Pereira LM, Phillips M, Ramlal H, et al. Third generation cephalosporin use in a tertiary hospital in Port of Spain, Trinidad: Need for an antibiotic policy. BMC Infect Dis. 2004; 4(1): 59.

45. Mulugeta T, Tarekegn M. Comparative retrospective drug use evaluation of ceftriaxone injection in Police and Black Lion Hospitals, EPA annual conference 2009: 17. Available at URL: http://epaethiopia.org/images/k2/38/32/abstract 2009.pdf

46. Hayashi Y, Paterson DL. Strategies for reduction in duration of antibiotic use in hospitalized patients. Clinical infectious diseases : an official publication of the Infectious Diseases Society of America. 2011;52(10):1232-40.

47. Gilbert GL. Knowing when to stop antibiotic therapy. The Medical journal of Australia. 2015;202(3):121-2.

48. Ventola CL. The Antibiotic Resistance Crisis: Part 1: Causes and Threats. Pharmacy and Therapeutics. 2015;40(4):277-83

49. Tapaneeyakul J, Lertsuwannawin S, Hosakul O. Drug use evaluation of ceftriaxone at Bumrungrad Hospital. Available at URL: http//www.pharmacy.mahidolac.th/ newspdf/ special project/2543-35.pdf. 